\title{
REPAIRING CUSTOMER TRUST FOLLOWING A BANKING CRISIS
}

Fridrik Eysteinsson, School of Business, University of Iceland, Reykjavik, Iceland Thorhallur Gudlaugsson, School of Business, University of Iceland, Reykjavik, Iceland

dx.doi.org/10.18374/IJBS-13-1.1

\begin{abstract}
This paper deals with how strongly banks' perceived repair efforts to influence their trustworthiness and elicit forgiveness following the banking crisis in Iceland in October 2008 relate to their trustworthiness, customer forgiveness and their trust towards them, how strongly trustworthiness relates to both forgiveness and trust and how strongly the two are related. The population of interest was the customers of the lcelandic banks. A convenience sample was used. The research questions are, "How strong is the relationship between the different repair efforts and the dimensions of trustworthiness?", "How strong is the relationship between the different repair efforts and a) forgiveness and b) trust", "How strong is the relationship between the different dimensions of trustworthiness and a) forgiveness and b) trust?" and "How strong is the relationship between customer forgiveness and trust?". The results of the research are that there were strong positive relationships between all the different repair efforts and all the trustworthiness dimensions, all the different repair efforts and forgiveness and trust and also all the trustworthiness dimensions and forgiveness and trust.
\end{abstract}

Keywords: Repair efforts; Trustworthiness; Customer forgiveness; Trust; Banks, Banking crisis 